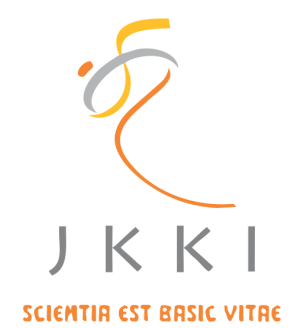

Jurnal Kedokteran dan Kesehatan Indonesia

Indonesian Journal of Medicine and Health

Journal homepage: https://journal.uii.ac.id/JKKI

\title{
Percutaneous retrieval of intracardiac fragmented hemodialysis catheter using a snare-loop catheter: A case report
}

\author{
Adhitya Ginting*1, Ketut Putu Yasa², Yan Efrata Sembiring ${ }^{1}$ \\ ${ }^{1}$ Department of Thoracic, Cardiac and Vascular Surgery, Faculty of Medicine, Universitas Airlangga/ dr.Soetomo \\ General Hospital, Surabaya, Indonesia \\ ${ }^{2}$ Division of Thoracic, Cardiac, and Vascular Surgery, Department of Surgery, Faculty of Medicine, Universitas \\ Udayana/ Sanglah General Hospital, Denpasar, Bali, Indonesia
}

Case Report

\begin{tabular}{l}
\hline \\
\hline ARTICLE INF O \\
\hline Keywords: \\
endovascular procedures, \\
intracardiac catheters, \\
equipment failure \\
*Corresponding author: \\
adhitya.gintingg@gmail.com \\
\hline DOI:10.20885/JKKI.Vol11.Iss2.art14 \\
\hline History: \\
Received: December 31, 2019 \\
Accepted: August 13, 2020 \\
Online: August 31, 2020 \\
\hline Copyright @2020 Authors. \\
This is an open access article \\
distributed under the terms \\
of the Creative Commons At- \\
tribution-NonCommercial 4.0 \\
International Licence (http:// \\
creativecommons.org/licences/ \\
by-nc/4.0/).
\end{tabular}

\section{ABSTRACT}

We presented a 60-year-old woman with an history of end-stage renal disease on regular hemodialysis, twice a week, came with a tunneled dialysis catheter (TDC) that was attached to the right internal jugular vein. TDC has been dysfunction since one week ago that was suspected as a result of thrombosis in the lumen of TDC. TDC was trimmed at the insertion of the jugular vein. And then a wire was inserted into TDC that has been trimmed. From Chest x-ray imaging, migration of fragmented TDC was found inside the heart chamber with wire inside the lumen. Fluoroscopy showed a picture of a fragmented TDC in the heart chamber with a wire inside the lumen. Retrieval of fragmented TDC used percutaneus snare loop method with wire guiding that was inserted through the left femoral vein. Fragmented TDC was removed successfully. Retrieval of the fragmented TDC through endovascular techniques is classified as a simple. Simple snare loop method is quite effective and very cheap compared to the commercial snare, open surgery or laparoscopic surgery that can be avoided.

Kami melaporkan seorang wanita 60 tahun dengan riwayat penyakit saat ini adalah gagal ginjal kronik dengan hemodialisa reguler dua kali seminggu. TDC terpasang di vena jugularis interna kanan. TDC mengalami disfungsi sejak 1 minggu lalu, dicurigai akibat dari trombosis yang terbentuk di dalam lumen kateter hemodialisa. TDC kemudian digunting sebagian pada insersi vena jugular dan wire dimasukkan ke dalam kateter hemodialisa tersebut. Dari pencitraan X-ray didapatkan migrasi bagian kateter hemodialisa berada di dalam ruang jantung dengan wire di dalam lumen kateter hemodialisa. Fluoroskopi menunjukkan gambaran sebagian kateter hemodialisa berada di ruang jantung dengan wire terpasang di dalam potongan lumen kateter hemodialisa. Ekstraksi sebagian kateter hemodialisa dilakukan menggunakan metode loop snare dengan akses guiding wire yang dimasukkan melalui vena femoralis kiri. Fragmen kateter kemudian berhasil dikeluarkan. Pengambilan fragmen melalui endovaskular tergolong teknik yang sederhana. Loop snare yang sederhana sudah cukup efektif dan murah dibanding komersial snare, sehingga pembedahan terbuka ataupun laparaskopik dapat dihindari.

\section{INTRODUCTION}

Hemodialysis requires access to the patient's blood vessels. Access to these vessels can be done through surgery or special procedures that can be performed by specialists. There are three common types of vascular access, 
they are Arterio-venous fistula (AV fistula), Arterio-venous graft (AV graft), and central venous catheter (also known as hemodialysis catheter). In this study, we will discuss about hemodialysis catheters and their complications. Hemodialysis catheter is a man-made flexible tube that is usually inserted into a large vein in the chest. Hemodialysis catheters can be inserted into a vein in the neck or in the groin. Every hemodialysis catheter has two holes called ports. One of the ports drain blood from the body that be cleaned through a dialysis machine and then the clean blood is returned to the body through the other ports. The place where the catheter enters the skin is also called the exit site. ${ }^{1}$

Hemodialysis catheter is a temporary hemodialysis access while waiting for AV fistula or AV graft surgery. Hemodialysis catheter is also used as an option if AV fistula or AV graft cannot be done. Hemodialysis catheter is inserted by the surgeon with ultrasound guiding or X-ray imaging in the operating room. Hemodialysis catheter can be used immediately after being inserted into a vein. The risk of infection increases in the area where hemodialysis catheter is attached both at the entrance to the body and in the bloodstream. In addition, there can be damage to the vein where the hemodialysis catheter is inserted. Hemodialysis catheter is inserted with the help of ultrasound so that they can be installed properly. The anesthetic use local anesthetic techniques. ${ }^{1}$

In general, the most preferred blood vessel access is AV fistula, because of the high average blood flow that can be achieved, and the low risk of infection problems and thrombosis. In addition, $\mathrm{AV}$ graft is the preferred blood vessel access, because the average blood flow that can be achieved is similar to the AV fistula. Hemodialysis catheter is blood vessel access last choice for hemodialysis because it can cause non-infectious complications which will be discussed later and compile infection, except for the initiation of hemodialysis while awaiting surgery. Tunneled Dialysis Catheter (TDC) is associated with higher rates of complications, morbidity and mortality compared to AV fistula or AF graft, and these complication are high costs of management.,

The most common non-infectious complication of TDC is hemodialysis catheter dysfunction. According to The National Kidney Foundation (NKF/DOQI) guidelines, hemodialysis catheter dysfunction is defined if extracorporeal blood flow cannot reach $300 \mathrm{ml} /$ min, with arterial pressure before pumping is less than negative $250 \mathrm{mmHg}$. The most common cause is thrombosis either inside or outside of the hemodialysis catheter lumen. Complication from the removal of hemodialysis catheters can also occur because the adhesion process in the cuff is not adequately formed. ${ }^{2}$

The rarest complication is migration of fragmented hemodialysis catheter into the heart. This can be caused by a fragile hemodialysis catheter tip or because a fragmented catheter is released into the heart during the replacement process from hemodialysis catheter. ${ }^{2}$

\section{CASE DESCRIPTION}

Our patient was a 60-year-old woman complaining about her TDC disfuncionality since one week ago. She has history of end-stage renal disease on regular hemodialysis, twice a week, came with TDC that was attached to the right internal jugular vein about six months. Consent was taken from her legal guardian.

The patient came by herself to our hospital because of TDC dysfunction during hemodialysis. The patient was asymptomatic. Physical examination showed a body temperature of $37.5^{\circ} \mathrm{C}$, TDC has been dysfunctional since 1 week ago because at that time, the extracorporeal blood flow hemodialysis was less than $300 \mathrm{ml} /$ min. Laboratory tests showed ureum $45 \mathrm{mg} / \mathrm{dl}$, creatinine $14 \mathrm{mg} / \mathrm{dl}$, and potassium $5 \mathrm{meq} /$ liter. The patient was planned for a replacing of the TDC with a temporary hemodialysis catheter in the operating room under local anesthesia. 


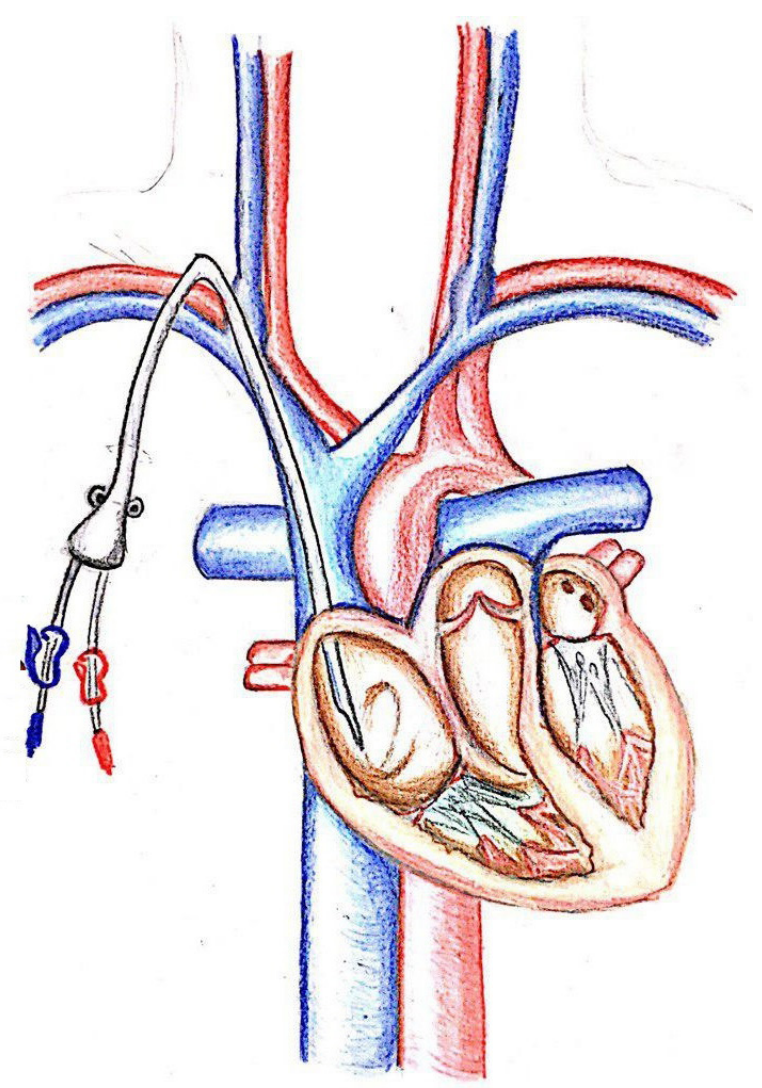

Figure 1. Tunneled Dyalisis Catheter (TDC) inserted into central vein. ${ }^{2}$

Patient was taken to the operating theater with stable blood pressure was 150/90 $\mathrm{mmHg}$, heart rate was 98 times per minute, respiratory rate was 22 times per minute, oxygen saturation was $99 \%$ without $\mathrm{O}_{2}$ support. ECG monitoring was installed on patient. Disinfection of the operating area used povidone iodine and alcohol. Then, draping of the patient used sterile ducts. TDC could not be aspirated using a $10 \mathrm{cc}$ syringe. This was suspected as a result of thrombosis that forms in the TDC lumen. TDC was trimmed at the insertion area (in the jugular vein). Wire was inserted into the fragmented TDC which has been trimmed, because the fragmented TDC was not good, then the fragmented TDC was aspirated into the blood vessels. Wire was retained, and then the patient was carried out on imaging using X-ray with a mobile C-Arm system. X-ray imaging revealed migration of the fragmented TDC inside the cardiac chamber with a wire in the lumen of the fragmented TDC (Figure 2 and 3). The procedure was stopped and the patient was planned for an extraction of the fragmented TDC in the hybrid operating theater. The condition of patient was stable with blood pressure was $140 / 90 \mathrm{mmHg}$, heart rate was 92 times per minute, respiratory rate was 20 times per minute, and oxygen saturation was 99\% saturation without hemodynamic support. 


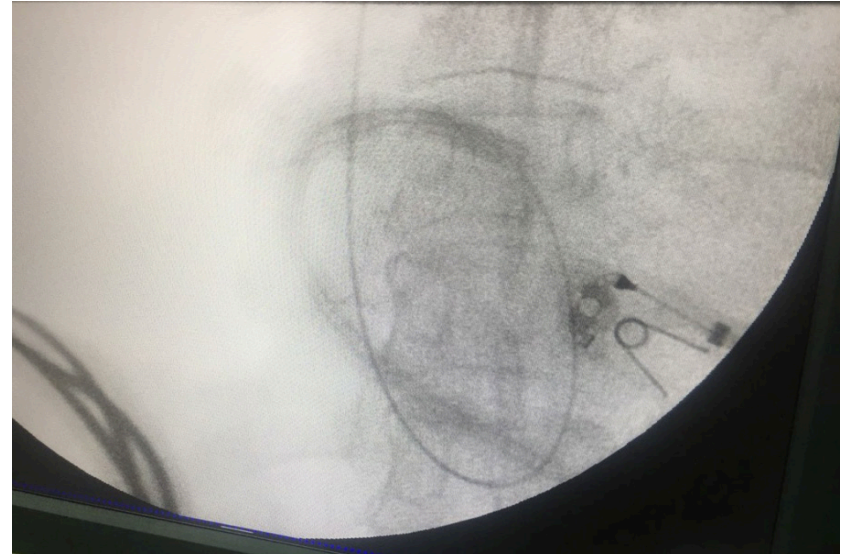

Figure 2. Fragmented TDC showed in Mobile C-arm X-ray

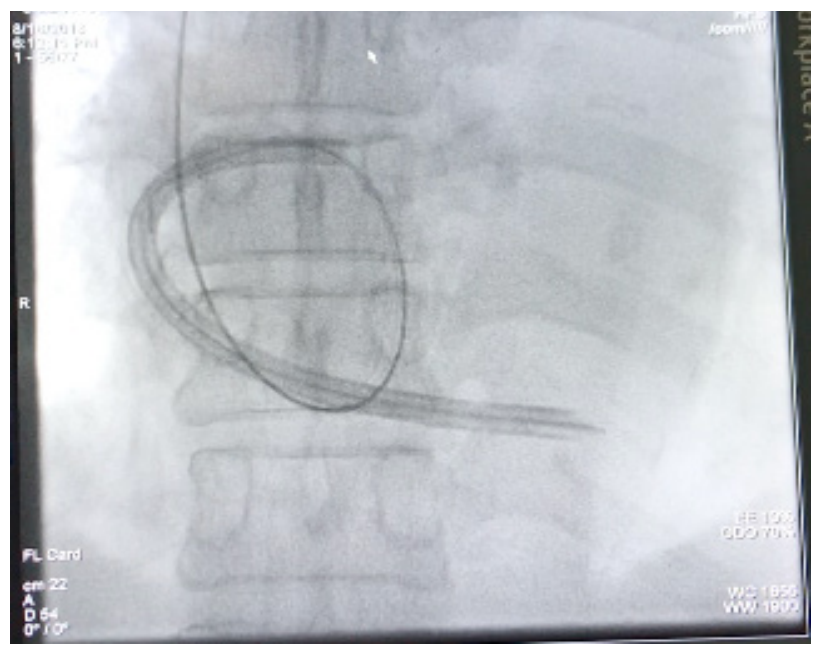

Figure 3. Fluoroscopy imaging showed fragmented TDC in heart chamber using the Mobile C-arm X-ray

The patient was prepared entering the hybrid operating theater for extraction of fragmented TDC. Once ready, the patient was brought into the hybrid operating theater with stable blood pressure was 140/90 $\mathrm{mmHg}$, heart rate was 90 times per minute, respiratory rate was 20 times per minute, and the oxygen saturation was $99 \%$ without hemodynamic support. ECG monitoring were installed on the patient. Disinfection of the operating area used povidone iodine and alcohol and then draping used sterile ducts. Fluoroscopy showed a picture of a fragmented TDC in the heart chamber with a wire attached to the lumen of the fragented TDC (Figure 3).

From fluoroscopy, the patient needed extraction of the fragmented TDC using the snare loop method (Figure 4) with wire guiding through the left femoral vein. After $11 \mathrm{Fr}$ sheath was inserted to the left femoral vein, the guiding wire was inserted into the femoral vein until they reached the fragmented TDC. Then a snare loop was inserted until it bound to the fragmented TDC and then the snare loop was locked. The snare loop was pulled slowly until it approached the left femoral vein. Fragmented TDC were extracted through an incision in the left femoral vein and then the incision area was covered layer by layer, the skin was covered by simple continuous suture. 

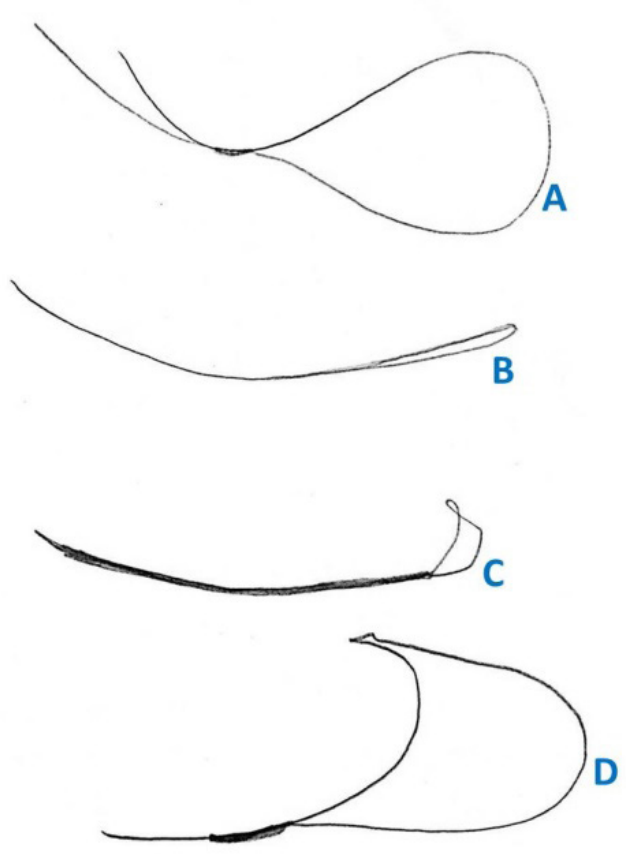

Figure 4. Four type of snare loops. From above,

(A) a simple snare loop is made with a 5-F, 0.038-inch Cobra 2 catheter endhole and an 18inch, 180-cm-long guidwire.

(B) Snare loop originates from the endoscopic set.

(C) Cook Medical (Bloomington, IN) IVC retrieval filter set.

(D) The last snare is the same snare loop as the first snare loop, only the apex of the guidewire loop is made kinking using forceps. ${ }^{4}$

After the procedure, we evaluated the fragmented TDC, that entered the patient's heart, was completely removed. There was no remaining fragmented TDC from the evaluation via fluoroscopy during the operation. After the operation. the patient was monitored in the ICU. The electrocardiogram and the physical examination were normal. There were not any major or minor complications such as arrhythmia, bleeding, vascular or cardiac perforation, or local hematoma. Two weeks after the patient discharged, the patient came to the outpatient and had no complaints.

\section{DISCUSSION}

The main complications of TDC are infection, occlusion, and mechanical. ${ }^{5}$ The infection consists of bacteremia and sepsis. The occlusion consists of either thrombosis or stenosis of the vein. Mechanical complications consist of bleeding due to previous puncture of blood vessels, pneumothorax, and very rarely is the migration of the catheter into the heart chamber. ${ }^{6}$

Using hemodialysis catheters in proper is very important because it can reduce the likelihood of complications. Repair of catheter dysfunction is preferred rather than try to replace the hemodialysis catheter and re-inserting in a different place. The causes of hemodialysis catheter dysfunction are fibrin formation in the lumen of the hemodialysis catheter, a curved catheter or malposition catheter, and acute or chronic thrombosis. Central venous stenosis resulting from an endothelial injury associated with central venous catheter placement. It can be decreased $\mathrm{AV}$ fistula flow or $\mathrm{AV}$ graft flow in 
the extremities. It is usually asymptomatic, but clinical symptoms can occur when it becomes getting more flow than it should, especially from $\mathrm{AV}$ fistula or $\mathrm{AV}$ graft. The risk factor is a long duration when inserting the catheter. ${ }^{6}$

Fibrin in the lumen of the hemodialysis catheter can be removed when the guiding wire was inserted during the replacement procedure or using balloon angioplasty. In the case of acute thrombosis, thrombolytic agent or thrombectomy can be used to retaining the patency, even with slight risk of bleeding during the procedure. Endovascular interventions such as percutaneous angioplasty are the best choice in the management of chronic central venous stenosis. $^{6}$

TDC is associated with infectious and noninfectious complications. It would increased morbidity and mortality of patient. ${ }^{7}$ These complications can occur right after inserting or can occur slowly during TDC usage. ${ }^{8}$ Thrombus can form in the lumen of hemodialysis catheters, which can lead to tissue complications such as pulmonary embolism, septic embolism, central venous stenosis, and cardiac arrhythmias. Optimal management of thrombus in the hemodialysis catheter lumen is still being debated. When a thrombus in a hemodialysis catheter is detected, patients are usually given anticoagulant therapy, using INR with the same target as patients with deep vein thrombosis for three months. Mostly, TDC is not removed (unless it is no longer needed). The duration of anticoagulation can vary depending on the severity of thrombosis, the risk of bleeding, and the need for using a hemodialysis catheter. ${ }^{9}$

Thrombus in the right atrium associated with a hemodialysis catheter is a serious complication, related to an average mortality rate of around $18 \%$. In a systematic review, about 71 reported cases has thrombus in the right atrium associated with a hemodialysis catheter, the authors recommend for removal of a hemodialysis catheter and using anticoagulation if the thrombus is less than $6 \mathrm{~cm}$. If patients have contraindications to anticoagulants (thrombus greater than $6 \mathrm{~cm}$ or abnormalities of the heart), thrombectomy can be considered. .,10 $^{9}$

Although the effort to make AV fistulas in hemodialysis patients increase, the prevalence of tunneled hemodialysis catheters remains high (National Vascular Access Initiative, Fistula First). In the United States, the use of TDC was $62.3 \%$ in hemodialysis patients in 2006. Infection associated with catheter placement and central venous stenosis is a common complication of TDC that makes them unfavorable compared to AV fistula and AV graft. Therefore TDC is only used while waiting for vascular access surgery or kidney transplantation. However, there are groups of patients who use TDC as long-term hemodialysis access because these patients have not a vascular access site remaining, poor vascular access for hemodialysis, or refusing to make vascular access. In these patients, unusual complications associated with the use of TDC may occur, for example, migration of TDC fragment into the heart. ${ }^{11}$

Chawla reviewed and proved that the interruption of TDC causing migration to the heart was very rare unless deliberately cut during the procedure to replace the TDC. A severed catheter tip can settle in the right heart chamber, vena cava or migrate to the pulmonary artery and its branches depending on its size and weight. ${ }^{12}$ Potential complications that can occur are perforation of the heart, valves, and blood vessels including the formation of thrombus and the phenomenon of embolism due to fragments that are cut off. Catheter fragments can be seen using X-ray. An echocardiogram or CT scan may be needed if fragments are not visible between the shadows of the heart. ${ }^{11,13}$

Taking a fragmented TDC that migrates depends on how long the fragment in the heart (the longer the likelihood of adhesions), there are risk factors for complications, and the site of the cut is located. Cutting is required if the fragment is in the right heart space and the proximal branches of the pulmonary artery due to complications that can occur there (infection, perforation, thrombosis, and arrhythmias). These complications can occur within a year, mostly within a month, and rarely within 2 years. 
Nellore and Trerotola described an unusual case of migrating fragments from the left to the pulmonary artery after 2 years of release. In his review of catheter embolism, Richardson noted that the highest mortality occurred in emboli in the right heart. Extracting fragments is needed either through percutaneous or through surgery. However, not all fragment embolization needs to be removed. If the fragment cannot be percutaneously removed because it is localized in a very distal place or has been present for a long time without symptoms and the patient decides not to operate (or surgery is contraindicated because of too high a risk of morbidity and mortality at that location), then the patient must be monitored closely strict. Prophylaxis of endocarditis and low-dose warfarin $(1 \mathrm{mg} /$ day) for at least 2 years (or low-dose aspirin) are highly recommended in such cases. High vigilance is needed in these patients because fragments that have long been able to migrate and cause complications. ${ }^{11,13}$

Every endovascular specialist will be confronted with a problem of a malfunctioning, interrupted, or migrating device that requires retrieval. The cause of migration from the catheter is very numerous, in this case, a fragmented TDC migrates into the cardiac chamber. The method for retrieval of fragments is various, in this case, we used the loop snare method., ${ }^{4,14}$

Snare and graspers for extracting fragments are widely sold in the market. However, it is easy to make a snare loop with standard 5-F and 180$\mathrm{cm}, 0.018$-inch guide wire angiographic catheters (Figure 4). Mallmann has reported success using this snare loop up to $100 \%$. The advantage of this type of snare loop are many size choices for this loop and the cost is not expensive. If the end of this loop is made kinking using forceps, this snare can be directed to the desired side. ${ }^{4,14}$

In almost all cases, it is possible to extract fragments without the need for surgery. In some cases, a large or stiff fragment can be taken and taken to a more superficial site where simple surgery with local anesthesia can be performed. The best time to extract fragments is just after the incident. A fragment becomes an alien corpus in the patient's body which can be a source of complications in the patient. Deciding which steps to take depends on what fragments will be taken, the position of the instrument system used, the approach to the fragment, and the process of bringing the fragment out through the safest and most easily accessible exit points. The loop snare used is a modified loop snare (Figure 5). In this case, the operator uses the endovascular loop snare technique (Figures 6 and 7).

Retrieval of intravascular or intracardiac of tunneled double lumen catheter fragment has various techniques. In the 2019 , the retrieval of the fragment of the catheter procedure was performed by Semadi. The procedure was performed under general anaesthesia and C-Arm guidance. About $7 \mathrm{~cm}$ Golf stick incision was made at the right Sedillot's triangle. The incision was done until the internal jugular vein was exposed. Purse string was made around prior incision with 4-0 non-absorbable monofilament suture. Under C-arm guidance, a mixter right angle clamp was inserted to retrieve the distal tip of dislodging double lumen catheter. The fragment of the catheter can be retrieved smoothly. ${ }^{15}$ No techniques have been recommended for retrieval procedure up until now in this case. The technique that will be used depends on the type and location of the hemodialysis catheter, it also depends on the experience of the operator.

In our case, the patient comorbid was endstage renal disease, so the patient needed a hemodialysis catheter for regular hemodialysis. But there are no any comorbid directly related to the procedure. Based on the location of the fragment of the catheter, the most likely complication is cardiac arrhythmia. Meanwhile, the complication for retrieval of intravascular or intracardiac of tunneled double lumen catheter fragment is the injury to the blood vessels so that thrombosis and bleeding can occur.

Our study has limitations. It is a single study, observational, and non-comparative study. This case is still rare. If there is another study found, it is better to use a case series or comparative study. The management of this case 
remains a challenge, endovascular specialists who experience a similar case can apply this procedure and it must be done by a competent doctor. Intracardiac or intravascular foreign body is a dangerous situation, but it could be managed early by knowing the exact site of the foreign body using a chest radiograph.

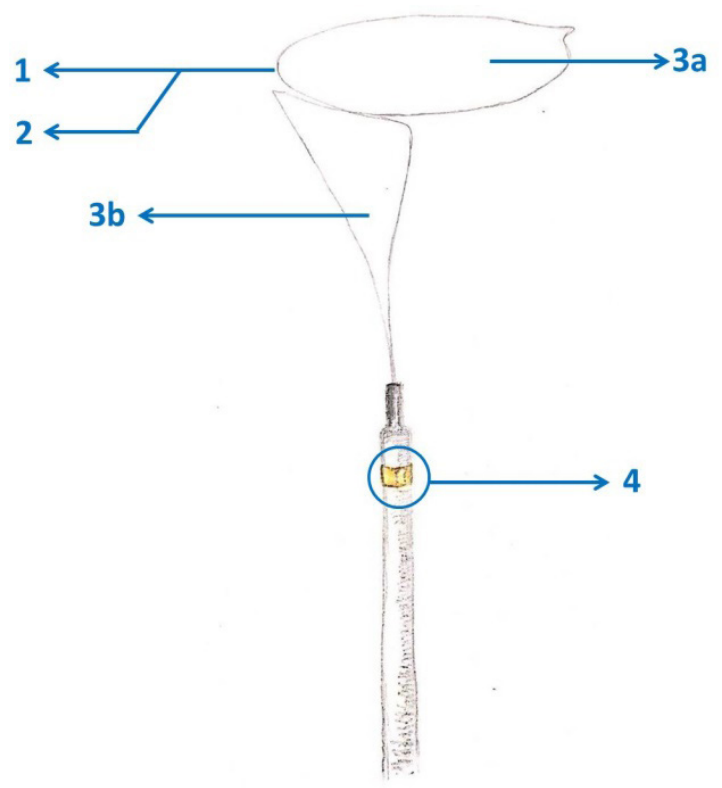

Figure 5. The modified loop snare parts. (1) variable diameter loop, (2) radioopaque loop, (3a) first plane, (3b) second plane, (4) gold marker. ${ }^{16}$
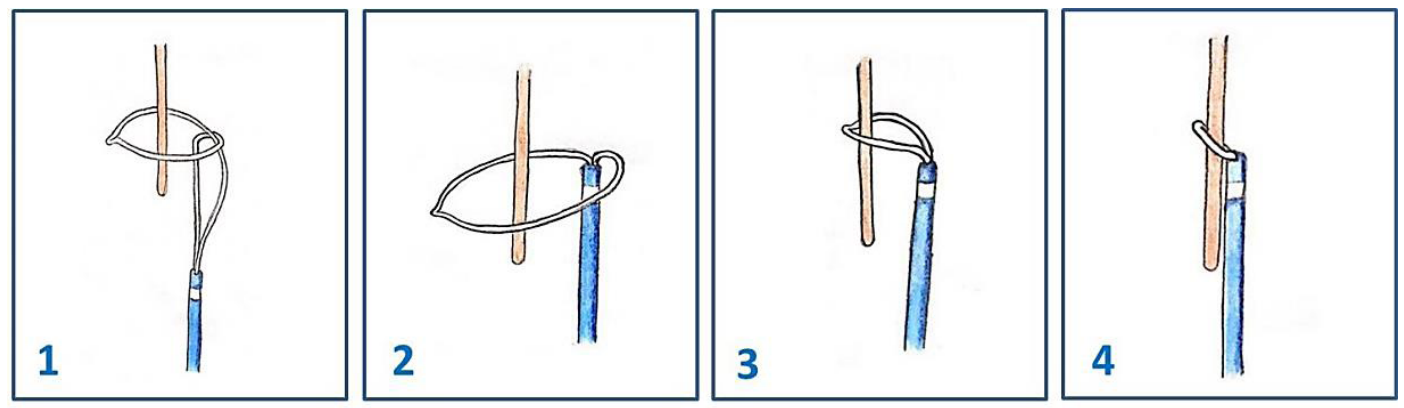

Figure 6. Endovascular loop snare technique uses first plane. ${ }^{16}$
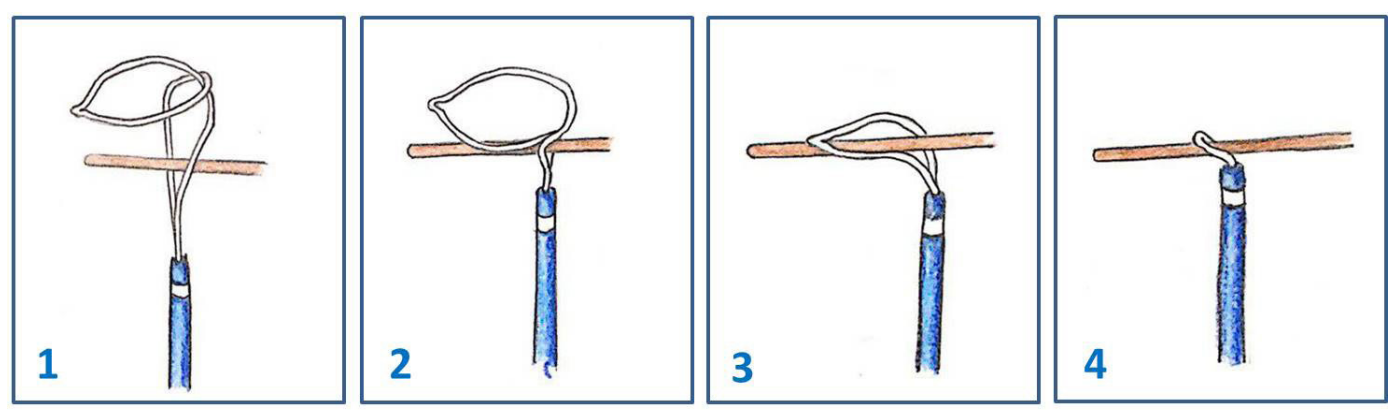

Figure 7. Endovascular loop snare technique uses the second plane. ${ }^{16}$ 


\section{CONCLUSION}

In conclusion, if there is a fragmented TDC, it is necessary to identify the location of the fragment using X-ray, fluoroscopy, or CT scan. After informing the patient, the fragments can be taken using snare especially in high-risk patients (patients at risk of endocarditis and fragments that are in the right heart and proximal to the pulmonary artery).

Retrieving fragments through endovascular techniques is simple, and there are many kinds of instruments for this purpose. Almost in all situations, a simple snare loop is quite effective and the cost is very cheap compared to commercial snare. Open surgery can be avoided but it depend on the cases.

\section{CONFLICT OF INTEREST}

The Authors have none to declare.

\section{ACKNOWLEDGEMENTS}

The Authors have none to declare.

\section{REFERENCES}

1. Barret B. Some facts about central venous catheters (hemodialysis catheters). Yhe Kidney Fund Canada. 2010;(February 2010):1-3.

2. Banerjee S. Dialysis catheters and their common complications: An update. ScientificWorldJournal. 2010;9:1294-9.

3. Zhu LN, Mou LJ, Ying-Hu LJ, Wei GN, Sun JF. Failure to place a tunneled hemodialysis catheter due to malformation of right internal jugular vein draining to subclavian vein. Journal of International Medical Research. 2018;46(6):2481-5.

4. Thompson K. Non-surgical retrieval of devices and foreign bodies. Endovascular Today. 2010;(July):29-32.

5. Adeel Ebad C, Davitt S, Gnanasekaran R, Khan A, Moran AM. Application of Hong's technique for removal of stuck hemodialysis tunneled catheter to pacemaker leads. Radiology Case Reports. 2017;12(1):97101.

6. Pereira K, Osiason A, Salsamendi J. Vascular access for placement of tunneled dialysis catheters for hemodialysis: A Systematic approach and clinical practice algorithm. Journal of Clinical Imaging Science. 2015;5(1):1-12.

7. Hong JH. An easy technique for the removal of a hemodialysis catheter stuck in central veins. Journal of Vascular Access. 2010;11(1):59-62.

8. Forneris G, Savio D, Quaretti P, Fiorina I, Cecere P, Pozzato M, et al. Dealing with stuck hemodialysis catheter: State of the art and tips for the nephrologist. Journal of $\mathrm{Ne}$ phrology. 2014;27(6):619-25.

9. Miller LM, MacRae JM, Kiaii M, Clark E, Dipchand C, Kappel J, et al. Hemodialysis tunneled catheter noninfectious complications. Canadian Journal of Kidney Health and Disease. 2016;3(1).

10. Wang L, Wei F, Jiang A, Chen H, Sun G, Bi $\mathrm{X}$. Longer duration of catheter patency, but similar infection rates with internal jugular vein versus iliac vein tunneled cuffed hemodialysis catheters: A single-center retrospective analysis. International Urology and Nephrology. 2015;47(10):1727-34.

11. Sequeira A, Sachdeva B, Abreo K. Uncommon complications of long-term hemodialysis catheters: Adhesion, migration, and perforation by the catheter tip. Seminars in Dialysis. 2010;23(1):100-4.

12. Hong JH. A breakthrough technique for the removal of a hemodialysis catheter stuck in the central vein: Endoluminal balloon dilatation of the stuck catheter. Journal of Vascular Access. 2011;12(4):381-4.

13. Zhou L, Yu S, Gou S, Shi M, Cui T, Fu P. Removing the incarcerated tunneled cuffed venous catheters: An experience from a single center. Blood Purification. 2018;46(3):246-7.

14. Amoretti N, Hauger O, Marcy PY, Hovorka I, Lesbats-Jacquot V, Fonquerne ME, et al. Foreign body extraction from soft tissue by using CT and fluoroscopic guidance: A new technique. European Radiology. 2010;20(1):190-2.

15. Semadi IN, Koerniawan HS, Irawan H. Retrieval of intravascular fractured fragment of tunnelled double lumen cathe- 
ter in hemodialysis patient. Open Access Macedonian Journal of Medical Sciences. 2019;7(1):124-6.

16. Micro M. objects from any angle. Three different types in various sizes make our snare the ideal interventional solu - tion for use in middle-sized to large vessels (MultiSnare $($ )), in distal smaller vessels (MultiSnare ${ }^{\circledR}$ Micro) and for supporting the implan. Multi-Snare®. 2015. http://www. pfmmedical.com 